\title{
Role of Learning Positive Personality Traits in the Promotion of Generational Resilience and Health Hakimeh Taghizadeh Ranibari $^{1}$
}

Date of submission: 14 Mar. $2021 \quad$ Date of acceptance: 05 May. 2021

\section{Original Article}

\begin{abstract}
INTRODUCTION: Throughout history, humans have always been prone to diverse experiences with different consequences. Consequently, a wide range of reactions is inevitable due to the different effects of these events on each person despite the same conditions. Therefore, it is indispensable to manage the physical and mental impacts of these events based on their magnitude. The present study aimed to assess the role of learning positive personality traits in the promotion of generational resilience and health.
\end{abstract}

METHODS: This applied research was conducted based on a comparative-causal design. The statistical population included 98 female high school students in Kerman who were selected by purposive sampling. The NEO Personality Inventory (Costa \& McCrae, 1985), the General Health Questionnaire (Goldberg, 1997), and the Connor-Davidson Resilience scale (CD-RISC) (2003) were used to collect the needed data. Data analysis was performed using the MannWhitney test and regression analysis.

FINDINGS: Based on the obtained results, learning exerted a significant effect on the promotion of the studied variables. Awareness and training on these strategies would be of great help in the development and improvement of resilience and health, as well as purposeful management of emotions in emergencies in people of all ages, especially the youth.

CONCLUSION: As evidenced by the results of the present study, it can be concluded that learning and developing positive personality traits significantly reinforce them and lead to the enhancement of the resilience and health of the next generation.

Keywords: Learning; Generational Resilience; Personality Traits; Positivism.

How to cite this article: Taghizadeh Ranjbari H. Role of Learning Positive Personality Traits in the Promotion of Generational Resilience and Health. Sci J Rescue Relief 2021; 13(2): 141-48.

\section{Introduction}

$\mathrm{H}$

uman life has been always intertwined with various events which can seriously affect people's minds, bodies, and souls in different ways. These events can vary from falling at school, cutting a finger with a kitchen knife, and a car accident to major natural and man-made disasters. In this regard, it is indispensable to manage the physical and mental impacts of these events. Therefore, a wide range of reactions is inevitable due to the different effects of these events on each person despite the same conditions. These different reactions seem to be related to the personality traits, tolerance level, and mental health of each person.

In human society, devastating consequences of these events can be minimized by practical training, purposeful cooperation, and strengthening the humanitarian partnership by the trained committed volunteers of non-profit organizations, such as the Red Crescent Society. The necessity and importance of this issue prompted Iran's Crisis Management Organization to formulate and enforce the first comprehensive law on crisis management, highlighting the responsibilities of the organizations involved in the crisis in the form of several committees.

In this regard, due to the defined duties of the Red Crescent Society, this organization was held responsible for the Rescue, Relief, and Public Education committee. Given the serious responsibility of the Red Crescent before, during, and after crises, it can be stated that an

1-Master of General Psychology, Azad University of Science and Research, Tehran; Kermanshah Branch, Red Crescent Society, Kermanshah, Iran

Correspondence to: Hakimeh Taghizadeh Ranjbari, Email:h.taghizadeh.r@gmail.com 
awareness of these essential issues is one of the most effective measures in the management of natural and man-made disasters and crises. Learning is the ultimate goal of any educational endeavor and results in improved reaction and behavior (1). It is a relatively permanent change in behavioral ability that occurs as a result of enhanced practice (2).

Training on scientific and practical skills can enhance the level of mental and skill performance of people for more effective functioning and reaction. Moreover, it empowers them to deal with unexpected life events (3). Research has demonstrated that education improves problemsolving skills, as well as creative and purposeful thinking in the face of unexpected situations (46). Adolescents suffer the most serious physical and mental damages, including post-traumatic stress disorder (PTSD), due to their specific physical and mental conditions, inadequate experience, and underdeveloped or immature coping strategies (7).

Crisis refers to the occurrence of a natural phenomenon in a certain space and a certain period of time, posing a serious threat to livelihoods (8). Disasters, due to their nature, occur suddenly and cause human, financial, and environmental losses (9). Community development through education and disaster management is of utmost importance in building a resilient community (10). Strengthening community resilience is among the proposed risk reduction programs in international organizations which have been pursuing their goals since 2005 (11).

In recent years, the positive psychology approach which puts a greater emphasis on human capabilities and potentials has come into the focus of psychologists. The ultimate goal of this approach is the identification of some strategies and techniques that result in human well-being and happiness. The most fundamental principle of this approach is human adaptability to the needs and threats of life. In this regard, resilience has found a special place in the fields of evolutionary psychology, family, and mental health (12).

Stressful events contribute greatly to the development of psychosomatic disorders; therefore, the analysis and strengthening of resilience to natural disasters have become a major field of interest in psychology, literature, engineering, and crisis management (13). The majority of experts referred to the resilience of ecological systems as the origin of modern resilience (14). Resilience is not only about the improvement of one's resilience in the face of crisis but also the maintenance and promotion of mental health.

This personality trait enables people to deal with life adversities with minimal damage and to use them for their own benefit (15). Resilience is the ability to withstand adversity and bounce back from difficult life events (16). This term is mainly used in crisis management (17). The situation stability can be achieved by focusing on resistance in different situations and in response to adverse events. It is a positive outcome that is an indicator of good adaptation and progress (18). Resilience is the ability to return to our original position and performance following an unexpected shock or disturbance.

The transition of resilience from a descriptive concept to a normative agenda provides golden opportunities for its improvement (19). Coping strategies used to deal with stress are strong determinants of positive or negative outcomes. The type of the selected coping strategies depends on the personality traits of individuals (20). In fact, this personality model affects stress-related processes by influencing the coping styles adopted by people (21). In times of crisis, the valuable concept of resilience is a unique approach in human society. In today's stressful world, it is enduring magic that increases people's empowerment and growth through interaction and practice (22).

The concept of changing conditions and intelligent resistance to change lies at the heart of this thinking (23). Since individuals' specific personality traits encourage the use of diverse coping strategies, they respond differently to stress (20). Individuals' personality traits provide patterns for the prediction of their behavior and mental states. Personality is at the core of individuals' psychological structure, helping them to develop specific lifestyles. In recent decades, scientists have gained an important position among experts by the introduction of some personality traits (24).

Problem-solving is a cognitive and learnable process used to find the best solution to achieve goals (25). Problem-solving as the highest level of human thought is a conscious, rational, purposeful activity and a skill that can be learned 
and strengthened (26). There is strong evidence that abilities and personality traits related to problem-solving can be trained and reinforced. They can act both as a protective factor against disorders and a development factor, performing a key role in the positive development of individuals. These capabilities can be strengthened through appropriate parenting, as well as education in schools and non-profit organizations in the form of educational programs in communities (27).

Mental health is one of the major global health indicators and a major matter of interest to researchers today (28). The World Health Organization (WHO) defines mental health as a state of complete physical, mental, and social wellbeing and not merely the absence of disease symptoms. Therefore, it encompasses not only the absence of mental illnesses but also the maximum level of functioning and reaction to a variety of life experiences in a flexible and meaningful manner. Consequently, there is a vital need for improved quality of the living environment, the ability to communicate with others, intelligent change, and logical resolution of conflicts.

Mental health is a state of well-being in which people realize their own abilities, can cope with the normal stresses of life, can work productively, and are able to make a great contribution to their community (29). The related studies have identified several factors as predictors of mental health, the most important of which are personality traits and resilience (30). Mental health problems which are indicative of the inability to cope with problems can be caused by uncompromising functions in each of the five broad personality domains (31).

In order to promote mental health and prevent social harm, it is necessary to develop or strengthen various abilities in people. This kind of training empowers and enables them to properly manage life events. To achieve this, education is the most effective method in the initial prevention of personal and social harm. Adolescence is the best age to receive these kinds of training (32). In light of the aforementioned issues, the present study assessed the role of learning positive personality traits in the promotion of generational resilience and health among the students who volunteered in the Red Crescent Society and nonvolunteer untrained students.

\section{Methods}

The current study aimed to evaluate the effectiveness of the training provided by the Red Crescent in emergency situations in a number of volunteer members who received Red Crescent multidimensional training in first aid, rescue, and psychological support according to a specific lesson plan and those who were not willing to participate in these classes (Training is a prerequisite of membership). This applied quantitative research was conducted based on a comparative-causal design. Volunteering for membership in the Red Crescent Society was considered the independent variable, and personality traits, resilience, and mental health were regarded as dependent variables.

The statistical population of this study included 98 female high school students in Kerman in 1999. The NEO Personality Inventory (Costa \& McCrae, 1985), The General Health Questionnaire (Goldberg, 1997), and The ConnorDavidson Resilience scale (CD-RISC) (2003) were used to collect the needed data. The data were analyzed using the Mann-Whitney test and regression analysis. After explaining the method and aim of the research, the participants were assured of the confidentiality of their responses; thereafter, they received the questionnaires. According to the formula for determining the sample size in quantitative research which assumes two domains, the preliminary sample was extracted from each community, the mean and standard deviation were calculated, and the sample size was obtained.

\section{Findings}

Neuroticism had the lowest mean, while the highest mean scores were related to conscientiousness and extroversion.

The most significant mean difference was in the neuroticism subscale which was lower in trained volunteers, as compared to that in nonvolunteers.

According to Table and Figure 2, the resilience mean score was higher in trained volunteers, as compared to that in non-volunteers.

According to the results, the mental health of volunteer students was about $15 \%$ higher than that of non-volunteer students [Figure3]. As evidenced by the results of general health subscales, 


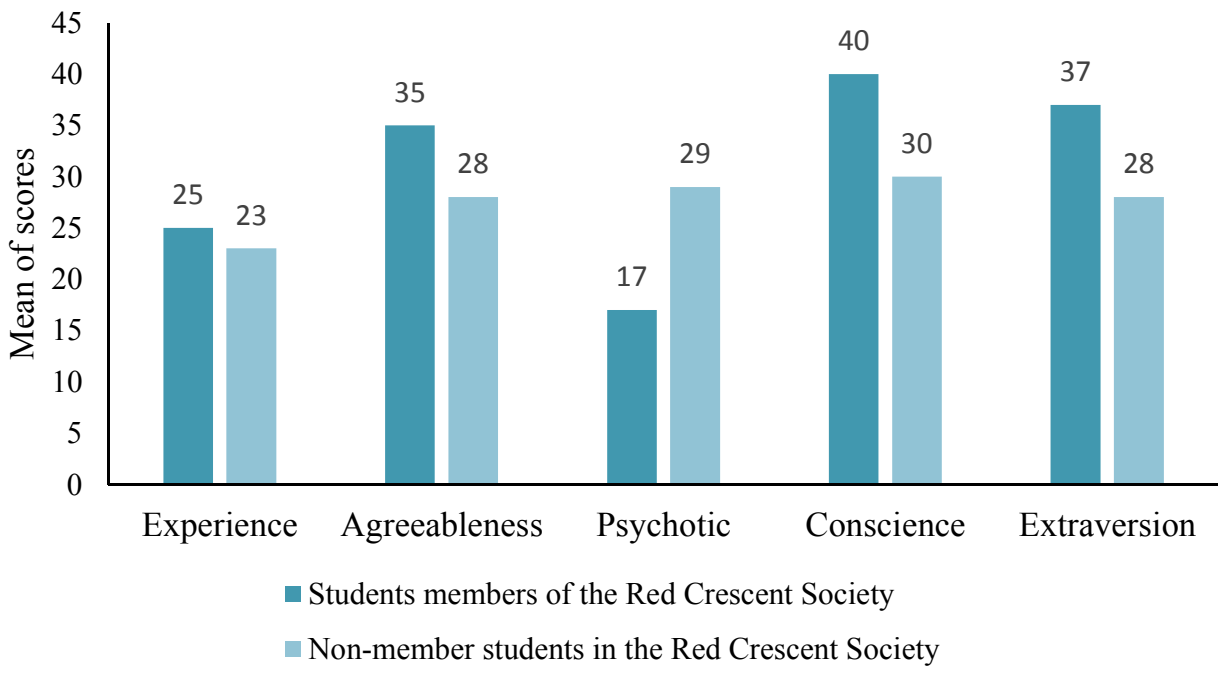

Figure 1. Comparison of the mean of personality traits subscales among volunteers and non-volunteers

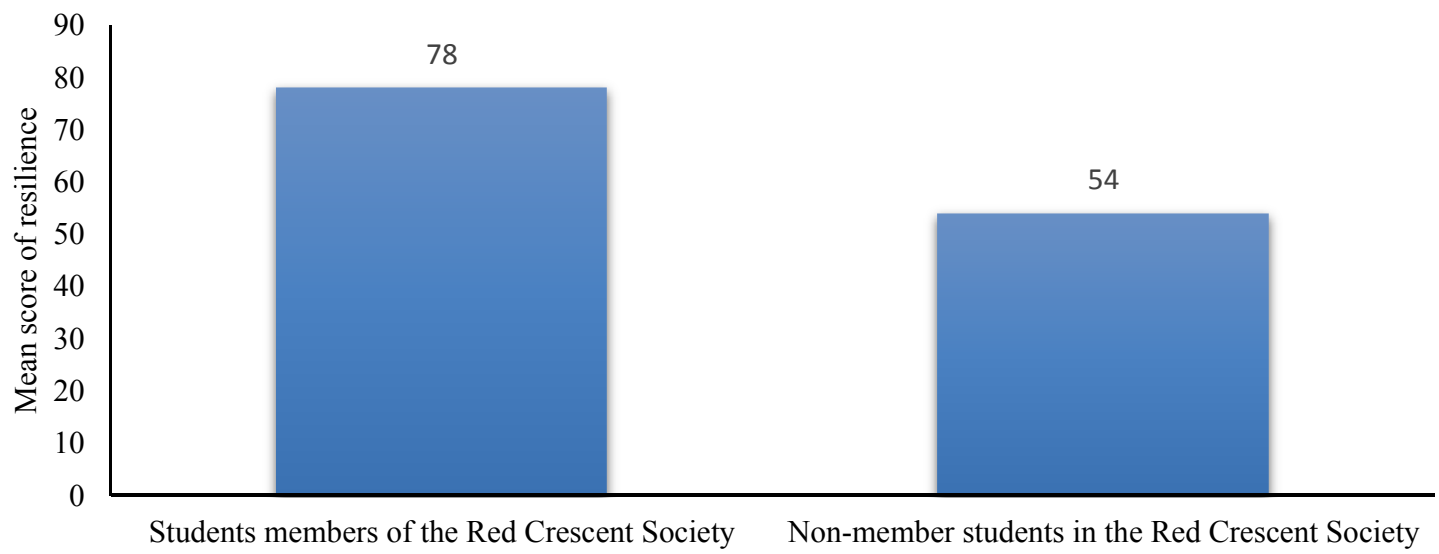

Figure 2. Comparison of the resilience scores of volunteers and non-volunteers

in non-volunteer students, the mean scores of physical symptoms, social dysfunction, and anxiety-insomnia showed a reduction of $5 \%$, $7 \%$, and $6 \%$, respectively. Moreover, severe depression was about $10 \%$ higher in nonvolunteers, in comparison with that in volunteers [Figure 4]. volunteer students obtained a higher general health mean score.

The most significant mean difference was observed in the subscale of severe depression and anxiety-insomnia which were lower in trained students who volunteer for the Red Crescent population [Figure 4]. All statistical analysis was performed in SPSS software (version 21).

There is a difference between the personality traits of trained students who volunteered in the
Red Crescent and non-volunteer students [Table $1]$.

Considering the P-value obtained in the above table, which is less than the significance level $(\alpha=0 / 05)$, it can be stated that the volunteers and non-volunteers differed significantly in the subscales of agreeableness, Conscientiousness, neuroticism, openness to experience, and extraversion. Volunteer students scored higher on personality traits (conscientiousness, agreeableness, neuroticism, openness to experience, and extraversion). The most significant mean difference was detected in the neuroticism subscale which was lower in volunteer students than nonvolunteers [Table 1].

The mean resilience score was significantly higher in volunteer students, as compared to that in non-volunteer students $\quad(\mathrm{P}$-value $<0.001)$ [Table2]. 


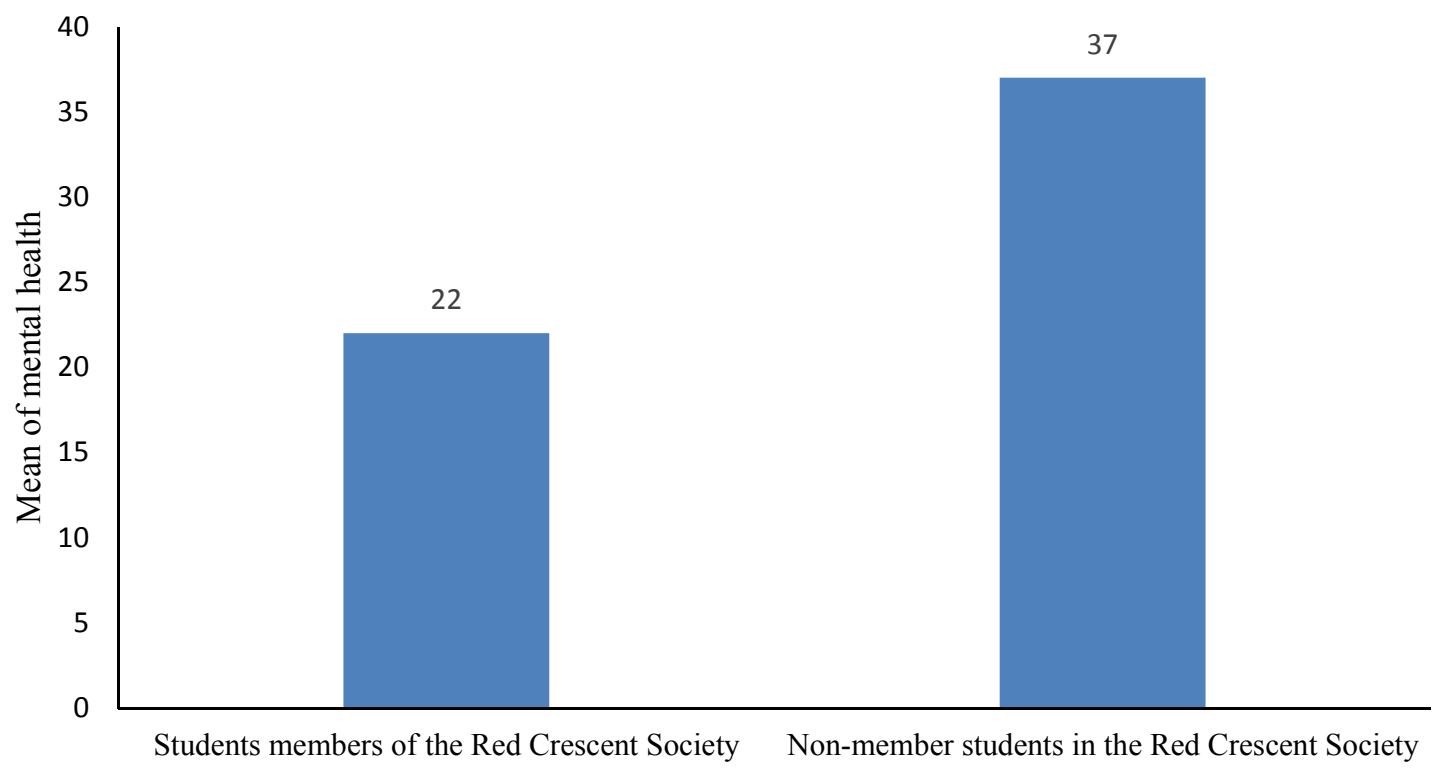

Figure 3. Comparison of the mean mental health scores of volunteers and non-volunteers

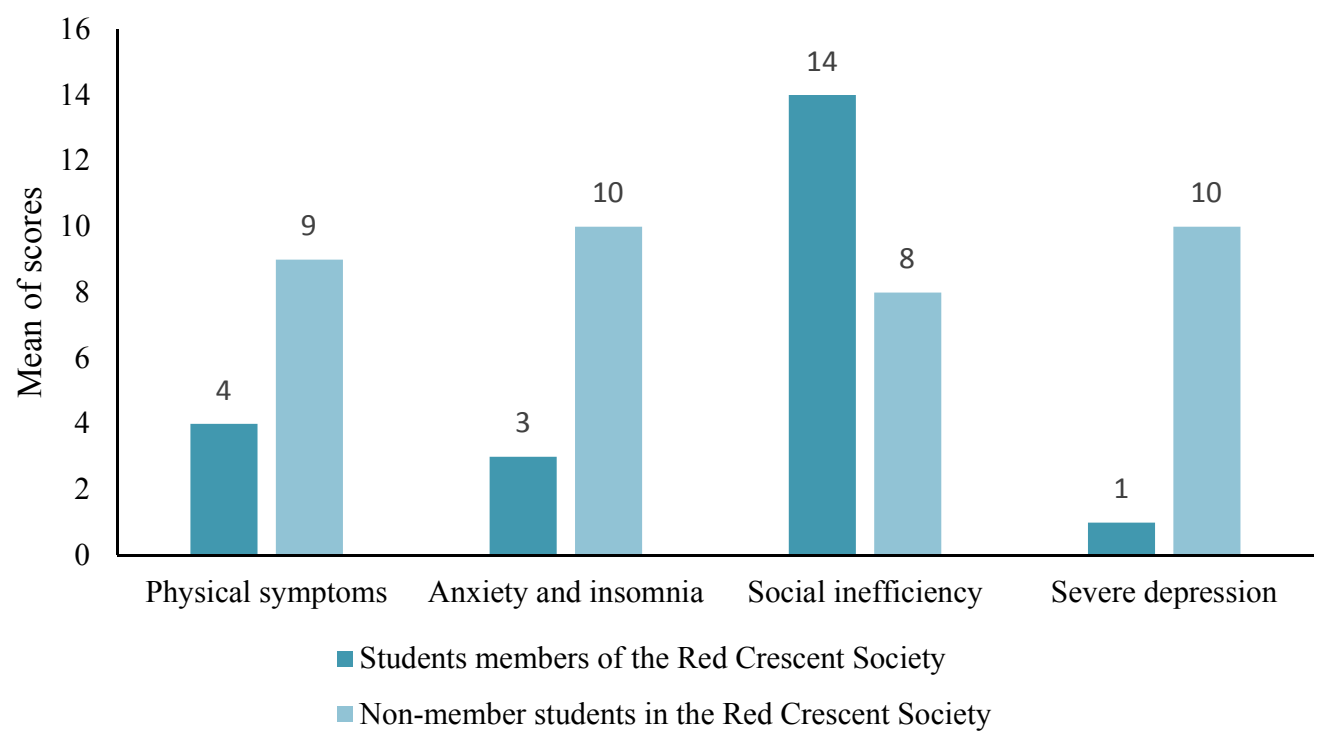

Figure 4. Comparison of the mean score for each general health subscale among volunteer and non-volunteer students

There are significantly differences between the students who volunteered in the Red Crescent and non-volunteer students in general health, mental health and subscales of them (somatic symptoms, anxiety-insomnia, social dysfunction, and severe depression)(P-value $<0.001)$ [Table 3].

The volunteer students obtained higher mean scores in conscientiousness, agreeableness, openness to experience, and extraversion; nonetheless, they scored lower on neuroticism. It can be justified on the ground that trained volunteer students consider their decisions to be logical and based on reality (33).

Furthermore, they use some social skills, such as the shrewd recognition of the deception of others in their personal relationships, and consider simplicity to be short-sighted. Since these people are less conservative, they usually demonstrate greater transparency in their social relationships (34).

Their other prominent characteristics include self-control, conscientiousness, thinking before acting, delayed gratification, observance of rules and norms, and prioritization of tasks. These 
people can effectively plan, organize, and perform the tasks assigned to them. Individual differences in these cases are based on conscientiousness. Conscientious people tend to be purposeful and determined which are prominent personality traits in successful and famous people (35). This field has been called the "tendency to succeed" (36). As a result, trained volunteer students are more likely to have such personality traits as conscientiousness, agreeableness, neuroticism, openness to experience, and extraversion.

According to the result, resilience was different between the two groups, that is to say, the mean resilience score is higher in volunteer students, as compared to that in non-volunteers. It can be justified on the

Table 1. Personality traits of member and non-member students

\begin{tabular}{|c|c|c|c|c|}
\hline \multirow{2}{*}{ Variable } & \multirow{2}{*}{ Subscales } & \multicolumn{2}{|c|}{ Mean (S.D) } & \multirow{2}{*}{ P-value } \\
\hline & & Member & Non-member & \\
\hline \multirow{5}{*}{ Personality traits } & Openness to experience & $25.38(4.88)$ & $23(6.11)$ & $<0.05$ \\
\hline & Agreeableness & $35.18(6.13)$ & $27.85(9.31)$ & $<0.001$ \\
\hline & Neuroticism & $16.59(7.98)$ & $28.67(8.54)$ & $<0.001$ \\
\hline & Conscientiousness & $40.26(6.99)$ & $29.61(10.26)$ & $<0.001$ \\
\hline & Extraversion & $37.22(5.91)$ & $27.61(9.88)$ & $<0.001$ \\
\hline
\end{tabular}

Table 2. Resilience of volunteer students and non-volunteers

\begin{tabular}{|c|c|c|c|c|}
\hline Variable & $\begin{array}{c}\text { Membership in the Red Crescent } \\
\text { Society }\end{array}$ & $\begin{array}{l}\text { Sample } \\
\text { Size }\end{array}$ & Mean (S.D) & P-value \\
\hline \multirow[t]{2}{*}{ Resilience } & $\begin{array}{c}\text { Students who volunteered in the Red } \\
\text { Crescent Society }\end{array}$ & 49 & $77.97(15.03)$ & \multirow[t]{2}{*}{$<0.001$} \\
\hline & Non-volunteers & 49 & $54.18(20.14)$ & \\
\hline
\end{tabular}

Table 3. Descriptive statistics of scores related to the general health of volunteers and non-volunteers

\begin{tabular}{ccccccccc}
\hline Variable & \multicolumn{2}{c}{ Mean } & \multicolumn{2}{c}{ Median } & \multicolumn{2}{c|}{ Standard deviation } & Range \\
\hline General health & 21.53 & 36.65 & 23 & 31 & 5.79 & 13.77 & 40 & 47 \\
Somatic symptoms & 4.22 & 9.102 & 3 & 8 & 2.28 & 4.79 & 12 & 16 \\
Anxiety and insomnia & 3 & 9.53 & 3 & 8 & 2.75 & 6 & 12 & 21 \\
Social dysfunction & 13.73 & 7.81 & 13 & 7 & 5.38 & 3.7 & 16 & 15 \\
Severe depression & 0.57 & 10.204 & 0 & 9 & 0.93 & 5.84 & 3 & 19 \\
\hline
\end{tabular}

ground that resilient people tend to maintain composed and are able to deal with adverse events since they do not have self-destructive behaviors and are emotionally tranquil (37). Furthermore, these people are known for their stubbornness, self-aggrandizement, repressive coping styles, and positive emotions (38).

They successfully adapt to hostile circumstances and achieve academic, emotional, and social success despite life pressures (39). Therefore, it is indicative of an interaction between humans and the environment. Resilient people are able to withstand adversities (40); as a result, the adverse effects are corrected, modified, or even eliminated. People with higher resilience have a strong tendency toward humanitarian activities and the provision of assistance to fellow human beings. They use positive emotion to get out of negative emotional experiences and bounce back to their psychological and physical state after a stressful experience (Difference in the resilience of individuals with diverse personality traits) (41).

General health (somatic symptoms, anxietyinsomnia, social dysfunction, and severe depression) was different between volunteer and non-volunteer students, and the mean general health score was lower in volunteers, as compared to that in non-volunteers. The results of can be justified on the ground that since the general health questionnaire actually measures the disease, a lower score is indicative of better health; therefore, the level of health was higher among volunteers.

\section{Discussion and Conclusion}

It can be argued that since volunteer students had been trained, they have higher levels of selfefficacy, self-esteem, self-worth, and competence; therefore, they have a more effective approach to solving life problems. They are not intimidated by 
unexpected events and failures by accurate assessment of their performance. Consequently, they are less affected by anxiety in the face of stressful life events and demonstrate higher levels of resilience and mental health.

The increased level of preparedness in times of emergency can significantly reduce stress and control thoughts and emotions. As a result, this awareness enables people to understand the crisis before making a decision, adopt more effective strategies, and manage the situation with minimal damage. Learning these strategies would be of great help in the development and improvement of resilience and health, as well as purposeful control of emotions in emergencies among people of all ages, especially the youth.

\section{Acknowledgments}

The author's deepest appreciation goes to the Red Crescent Society, the Ministry of Education, and the Psychology and Counseling Organization.

\section{Conflict of Interests}

Authors declared no conflict of interests regarding the publication of the present study.

\section{References}

1. Annetta LA, Folta E, Klesath M. V-Learning: distance education in the 21 st century through $3 \mathrm{D}$ virtual learning environments. Berlin, Germany: Springer Science \& Business Media; 2010.

2. Forsyth B, Kimble C, Birch J, Deel G, Brauer T. Maximizing the adaptive learning technology experience. J Higher Educ Theory Pract 2016;16: 4.

3. Esnaashari N, Fooladchang $M$, Daryapour E. Effectiveness of creativity training using Lego on self-confidence and problem solving of 4-6 year old children. Res Cognitive Behav Sci 2018; 7(2): 23-38.

4. Young LP. Imagine creating rubrics that develop creativity. English J 2009; 99(2): 74-9. (In Persian)

5. Kandemir MA, Gur H. Creativity training in problem solving: a model of creativity in mathematics teacher education. $\mathrm{N}$ Horiz Educ 2007; 55(3): 107-22.

6. Aldous CR. Creativity, problem solving and innovative science: insights from history, cognitive psychology and neuroscience. Int Educ J 2007; $8(2)$ : 176-87.

7. Sadock BJ. Kaplan \& Sadock's synopsis of psychiatry: behavioral sciences, clinical psychiatry. New Jersey: Recording for the Blind \& Dyslexic; 2006.

8. Oliveira CS, Roca A, Goula X. Assessing and managing earthquake risk. Berlin, Germany:
Springer; 2014.

9. Rajabi M, Hejazi M, Roostaei S, Aali N. The role of geomorphology factors in the occurrence of natural hazards in rural settlements case study: city of Saqez. Quantit Geomorphol Res 2018; 7(2): 18395. (In Persian)

10. Wikström A. The challenge of change: planning for social urban resilience: an analysis of contemporary planning aims and practices. New York: Semantic Scholar; 2013.

11. Mileti D. Disasters by design: a reassessment of natural hazards in the United States. Washington D.C: Joseph Henry Press; 1999.

12. Campbell-Sills L, Cohan SL, Stein MB. Relationship of resilience to personality, coping, and psychiatric symptoms in young adults. Behav Res Ther 2006; 44(4): 585-99.

13. Manyena SB. Disaster resilience: a question of multiple faces and multiple spaces? Int J Disaster Risk Reduct 2014; 8: 1-9.

14. Newell JP, Cousins JJ. The boundaries of urban metabolism: towards a political-industrial ecology. Progr Hum Geography 2015; 39(6): 702-28.

15. Ahmadi S. Examining the family structure, generalities and concepts. Third National Conference on Strategies for Development and Promotion of Educational Sciences, Psychology, Counseling and Education in Iran, Tehran, Iran; 2015. (In Persian)

16. Norman W, O’Sullivan C, Mguni M, Penny J. Adapting to change: the role of community resilience. London: Young Foundation; 2012.

17. Bujones AK, Jaskiewicz K, Linakis L, McGirr M. A framework for analyzing resilience in fragile and conflict-affected situations. New York: Columbia University SIPA; 2013

18. Marchese D, Reynolds E, Bates ME, Morgan H, Clark SS, Linkov I. Resilience and sustainability: similarities and differences in environmental management applications. Sci Total Environ 2018; 613: 1275-83.

19. Contreras D, Blaschke T, Hodgson ME. Lack of spatial resilience in a recovery process: case L'Aquila, Italy. Technol Forecast Soc Change 2017; 121: 76-88.

20. Bartley CE, Roesch SC. Coping with daily stress: the role of conscientiousness. Pers Individ Differ 2011; 50(1): 79-83.

21. Leandro PG, Castillo MD. Coping with stress and its relationship with personality dimensions, anxiety, and depression. Proc Soc Behav Sci 2010; 5: 1562 73.

22. Masten AS. Ordinary magic: resilience in development. New York: Guilford Publications; 2015.

23. Pisano U. Resilience and sustainable development: theory of resilience, systems thinking. Eur Sustainable Dev Netw (ESDN) 2012; 26: 50. 
24. Amrai K, Farahani A, Ebrahimi M, Bagherian V. Relationship between personality traits and spiritual intelligence among university students. Proc Soc Behav Sci 2011; 15: 609-12.

25. Meissner H. Creativity in mathematics education. The Proceedings of the 12th International Congress on Mathematical Education, Seoul, Korea; 2015.

26. Nolen-Hoeksema S, Fredrickson B, Loftus GR, Lutz C. Introduction to psychology. Massachusetts: Cengage Learning; 2014.

27. Park N. Character strengths and positive youth development. Ann Am Acad Political Soc Sci 2004; 591(1): 40-54.

28. Babamiri M, Mohammadi Y, Barati M, Rashidi S. Relationship between happiness and mental health status among high school female students: a descriptive analytic study. Nurs Midwifery J 2017; 14(11): 942-51. (In Persian)

29. Ding N, Berry HL, O'Brien LV. One-year reciprocal relationship between community participation and mental wellbeing in Australia: a panel analysis. Soc Sci Med 2015; 128: 246-54.

30. Bar-On R. The Bar-On model of emotional-social intelligence (ESI). Psicothema 2006; 31: 13-25.

31. Keyes CL. Promoting and protecting mental health as flourishing: a complementary strategy for improving national mental health. Am Psychol 2007; 62(2): 95.

32. Azad H, Nejat H. Mental health from Ellis' point of view. J Fundamentals Mental Health 1999; 1(4): 222-30. (In Persian)

33. Sheikholeslami R, Khayer M. Investigation about motivational beliefs and use of English language learning strategies among students. Quart J Psychol 2006; 10(1): 22-33. (In Persian)

34. Haghshenas H, Chamani AR, Firouzabadi A. Personality and mental health differences of gifted high schools students compared to ordinary high schools students. J Fundamentals Mental Health 2006; 8(29-30): 57-66. (In Persian)

35. Digman JM. Personality structure: emergence of the five-factor model. Ann Rev Psychol 1990; 41(1): 417-40.

36. McCrae RR, Costa Jr PT. A contemplated revision of the NEO five-factor inventory. Pers Individ Differ 2004; 36(3): 587-96.

37. Connor KM, Davidson JR. Development of a new resilience scale: the Connor Davidson resilience scale (CD- RISC). Depress Anxiety 2003; 18(2): 76-82.

38. Bonanno GA. Loss, trauma, and human resilience: have we underestimated the human capacity to thrive after extremely aversive events? Am Psychol 2004; 59(1): 20-8.

39. Davis I, Izadkhah YO. Building resilient urban communities. Open House Int 2006; 31(1): 11-21.

40. Rutter M. Resilience concepts and findings: Implications for family therapy. J Family Ther 1999; 21(2): 119-44.

41. Tugade MM, Fredrickson BL. Resilient individuals use positive emotions to bounce back from negative emotional experiences. J Pers Soc Psychol 2004; 86(2): 320 . 